\title{
Effect of Strain-Dependent Hydraulic Conductivity of Coal Rock on Groundwater Inrush in Mining
}

\author{
Haifeng Lu $\left(\mathbb{D},{ }^{1}\right.$ Nan Shan, ${ }^{2}$ You-Kuan Zhang, ${ }^{3,4,5}$ and Xiuyu Liang $\mathbb{D}^{3,4,5}$ \\ ${ }^{1}$ School of Earth and Environment, Anhui University of Science and Technology, Huainan, Anhui 232001, China \\ ${ }^{2}$ Nanjing Institute of Environmental Sciences, Ministry of Ecology and Environment of the People's Republic of China, Nanjing, \\ Jiangsu 210042, China \\ ${ }^{3}$ School of Environmental Science and Engineering, Southern University of Science and Technology, Shenzhen, \\ Guangdong 518055, China \\ ${ }^{4}$ State Environmental Protection Key Laboratory of Integrated Surface Water-Groundwater Pollution Control, Southern University of \\ Science and Technology, Guangdong 518055, China \\ ${ }^{5}$ Shenzhen Municipal Engineering Lab of Environmental IoT Technology, Southern University of Science and Technology, \\ Shenzhen 518055, China
}

Correspondence should be addressed to Xiuyu Liang; liangxy@sustech.edu.cn

Received 26 July 2020; Revised 3 December 2020; Accepted 8 December 2020; Published 23 December 2020

Academic Editor: Jingmin $\mathrm{Xu}$

Copyright (C) 2020 Haifeng Lu et al. This is an open access article distributed under the Creative Commons Attribution License, which permits unrestricted use, distribution, and reproduction in any medium, provided the original work is properly cited.

\begin{abstract}
Hydraulic conductivity is an important parameter for predicting groundwater inrush in coal mining worksites. Hydraulic conductivity varies with deformation and failure of rocks induced by mining. Understanding the evolution pattern of hydraulic conductivity during mining is important for accurately predicting groundwater inrush. In this study, variations of hydraulic conductivity of rock samples during rock deformation and failure were measured using the triaxial servo rock mechanic test in a laboratory. The exponential formula of hydraulic conductivity-volume strain was proposed based on the experimental data. The finite-difference numerical model FLAC ${ }^{3 \mathrm{D}}$ was modified by replacing constant hydraulic conductivity with the strain-dependent hydraulic conductivity. The coupled water flow and rock deformation and failure were simulated using the modified model. The results indicate that in the early time, the rocks undergo elastic compression with increasing rock strain, resulting in a decrease in hydraulic conductivity; then, the microcracks and fissures appear in the rock after it yields results in a sudden jump in hydraulic conductivity; in the later time, the hydraulic conductivity decreases gradually again owing to the microcracks and fissures that were compacted. The conductivity exponentially decreases with the volumetric strain during the periods of both elastic compression and postyielding. The simulated stress-strain curves using the modified model agree with the triaxial tests. The modified model was applied to the groundwater inrush of a coal mining worksite in China. The simulated water inflow agrees well with the observed data. The original model significantly underestimates the water inflow owing to it to neglect the variations of the hydraulic conductivity induced by mining.
\end{abstract}

\section{Introduction}

Coal is a reliable and affordable source of energy in many countries, such as China. It is responsible for approximately 40 percent of the electricity generated globally. The production of coal, however, is constrained by various disasters, such as water inrushes and coal and gas outbursts in working faces during mining [1]. The surrounding aquifers of coal seams are the source of water inrush in the working faces.
The groundwater in the surrounding aquifers will discharge into the working faces during mining. Accurate prediction of the water inflow is important in designing the coal mine drainage system, as well as enhancing coal production efficiency, and hence, was widely studied in previous researches. The methods to predict water inflow from working face include engineering analogy [2], empirical formulas [3, 4], hydrokinetic analysis $[5,6]$, analytical modeling [7-9], and numerical simulation [10-13]. The analogy and empirical 
formula methods are simple and easy to operate. However, due to the different geological environments of the working face, the above two methods lack pertinence and accuracy. The analytical method simplifies the geological model such that the calculation results do not completely reflect the geological and hydrogeological environment in which the working face is located. The numerical simulation method is a suitable method for calculating the water inflow from the working face. It is based on the conceptual model of hydrogeology that reflects the hydrodynamic characteristics and specific boundary conditions of the water-bearing medium in the surrounding rock stope. It can make up for the defect in other methods that have difficulty describing the process of rock mass destruction and groundwater seepage caused by mining.

Hydraulic conductivity is an important parameter for predicting groundwater inrush in mining worksites. The hydraulic conductivity varies with deformation and failure of rocks induced by mining. Understanding the hydraulic conductivity evolution pattern during mining is very important to predict groundwater inrush accurately. However, the influence of mining disturbance on hydraulic conductivity is not considered in the existing numerical models for predicting water inrush. With the exploitation of coal seams, the damage of surrounding rock is gradually developed, and its permeability continues to increase. The hydraulic fracturing experiment points out that with the increase of water pressure, and the development of microfissures, the change in hydraulic conductivity becomes obvious $[14,15]$. Souley et al. [16] suggested that the damage of rock will cause increases of hydraulic conductivity. Wang and Park [17] also found that the increase in hydraulic conductivity caused by rock rupture is a controlling factor for water inrush from the mine floor. Schatzel et al. [18] and Adhikary and Guo [19] have carried out an in situ pressure water test on the roof of the longwall working face and measured the hydraulic conductivity changes of strata in the mining overburden fissure zone. The measured hydraulic conductivity increases by three orders of magnitude during mining. The laboratory triaxial test also revealed that the hydraulic conductivity of rock is not a constant but changes with the evolution characteristics of rocks' internal structure during the stress-strain process. The relationship between hydraulic conductivity and stress, for rocks under pressure, shows that the rock pore was compacted and the hydraulic conductivity changes with increasing stress in the elastic stage [20-23]. At this stage, the stress-dependent hydraulic conductivity can be used. However, when the rock enters the plastic stage, the stress did not change significantly while the strain continued to increase. At this time, the stress-dependent hydraulic conductivity cannot be used to represent the changes of hydraulic conductivity. Derek and Mao [24] and Stormont and Daemen [25] suggested using the rock deformation as a valid factor to describe the changes of hydraulic conductivity.

As mentioned above, the existing studies investigated the variations of hydraulic conductivity induced by rock deformation based on the analysis of stress and strain. However, to the best knowledge of the authors, a numerical model having a capacity to consider the variations of hydraulic conduc- tivity for predicting water inflow in coal working face has not been reported in the existing literatures. This study is aimed at filling this knowledge gap by proposing a formula of hydraulic conductivity-volume strain and modified the existing numerical model to combine this formula. In this study, the formula of hydraulic conductivity-volume strain was established according to the triaxial hydraulic conductivity test. The finite-difference numerical model FLAC ${ }^{3 \mathrm{D}}$ was modified by replacing constant hydraulic conductivity with the strain-dependent hydraulic conductivity. The modified model was applied to the groundwater inrush of a coal mining worksite in China. This paper is organized as follows. We first present the laboratory experiment and numerical modeling in Section 2, then describe the results and discussion in Sections 3, and apply the modified model to the groundwater inrush of a coal mining worksite in Section 4, followed by summary and conclusions in Section 5 .

\section{Methodology}

2.1. Triaxial Hydraulic Conductivity Test. MTS815.03 electrohydraulic servo rock mechanic test system was used in the triaxial hydraulic conductivity test (Figure 1(a)). The loading system is displayed in Figure 1(b), and the basic principle of the test is presented in Figure 1(c). In Figure 1(c), $\sigma_{1}$ is the axial pressure, $\sigma_{3}$ is the confining pressure, $p_{1}$ is the upper water pressure of the rock sample, and $p_{2}$ is the lower water pressure of the rock sample. The permeable plates at the upper and lower ends of the rock sample are steel plates with many uniformly distributed holes. Before the experiment, the water pressure was uniformly applied to the bottom of the rock sample. The upper and lower parts were imposed on uppressing and underpressing pressure heads, respectively. The test is carried out according to the following steps. First, the sample was saturated with water in a vacuum immersion device during the test. Then, we used the polytetrafluoroethylene pyrocondensation plastics to seal the surrounding of the rock sample densely, which prevent the fluid leakage from the gap between the protective cover and the rock sample. Finally, the sample was placed in a servo triaxial cylinder for a pressure test.

Two experimental methods are usually used to measure hydraulic conductivity during triaxial compression: the transient flow method (for low hydraulic conductivity) and the steady-state flow method (for high hydraulic conductivity) $[5,6,26,27]$. In this study, the transient method was adopted, because the initial hydraulic conductivity of the rock sample is very low. According to the ground stress level, the confining pressure was determined to be $5 \mathrm{MPa}$ in the test. Initially, the same water pressure was applied at both top and bottom of the rock sample, i.e., $p_{1}=p_{2}=4 \mathrm{MPa}$. Then, the water pressure $p_{2}$ at the bottom of the rock sample is reduced to generate the water pressure difference between the top and bottom of the sample $\left(\Delta p=p_{1}-p_{2}=1.5 \mathrm{MPa}\right)$. With each level of axial stress applied, the process of axial deformation and the change of water pressure with time were measured. The stress, strain, and hydraulic conductivity were measured every $20 \mathrm{~s}$ during the test. On the basis of the measured data, the hydraulic conductivity of rock is calculated by the 


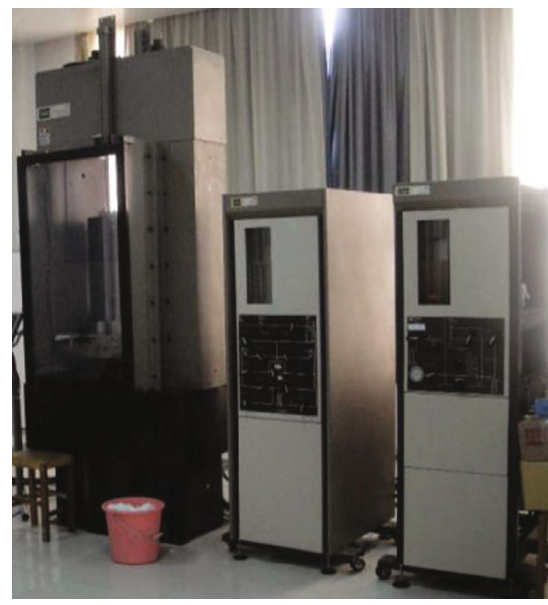

(a)

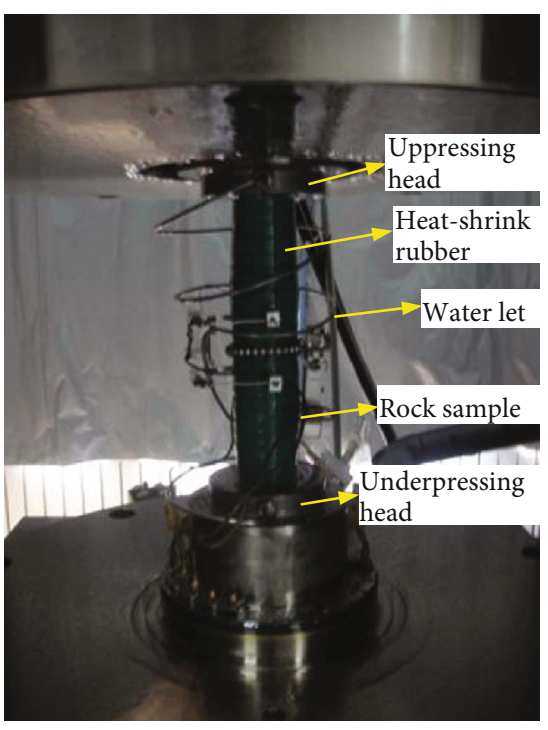

(b)

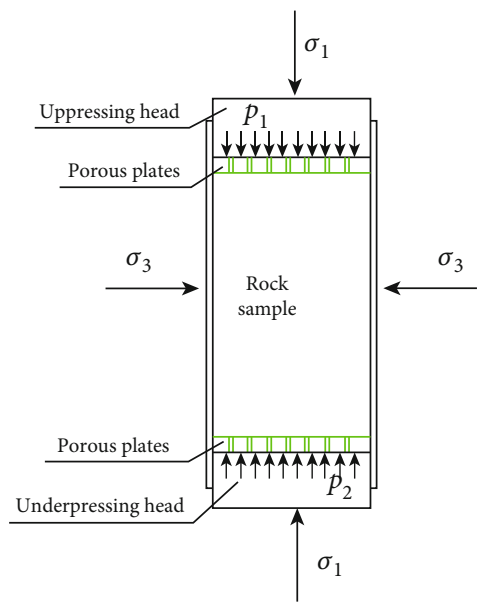

(c)

FIGURE 1: MTS rock mechanic testing system and assembled rock sample: (a) testing system, (b) rock sample assembly, and (c) diagram of the triaxial test.

following formula [28]:

$$
K=2.40129 \times 10^{9} \times \frac{\operatorname{L1g\Delta p}}{A \Delta t}
$$

where $K$ is the hydraulic conductivity, $L$ is the sample height, $A$ is the cross-sectional area, $\Delta p$ is the pore water pressure difference applied between both end planes of the rock sample, and $\Delta t$ is the data measurement interval.

The rock samples were taken from a borehole at the Xifeng shaft of Pansan coal mine. The mine is located in Fengtai County, Huainan City, Anhui Province, China. The sampling position was No. 8 coal seam roof and floor. The lithology of the samples collected was siltstone, mudstone, and fine sandstone. Among them, fine sandstone and siltstone had compact and hard lithology, with occasional fissures while mudstone was dense with no fissures. Each rock sample was divided into three groups. The parameters and the results of the triaxial tests are summarized in Table 1.

2.2. Numerical Modeling. The triaxial hydraulic conductivity test showed that the rock becomes strain softening after the stress reaches peak strength. With the rock gradually deforms, the fissure volume expansion accelerates, and the hydraulic conductivity increases rapidly. The strength of rock also decreases and approaches the residual strength gradually. In this study, we adopted the FLAC ${ }^{3 \mathrm{D}}$ strain-softening module to describe these processes. Based on the relationship between the volume strain and the hydraulic conductivity (the details are presented in Section 3.2), the coupling fluid-solid modeling was carried out. The strain-softening behavior and hydraulic conductivity evolution process of the rock samples were simulated (the details are presented in Section 3.3). 
TABLE 1: Parameters and results of the triaxial hydraulic conductivity test.

\begin{tabular}{|c|c|c|c|c|c|c|c|c|}
\hline \multirow[t]{2}{*}{$\begin{array}{l}\text { Lithology } \\
\text { description }\end{array}$} & \multirow[t]{2}{*}{$\begin{array}{l}\text { Sampling } \\
\text { horizon }(\mathrm{m})\end{array}$} & \multicolumn{2}{|c|}{ Sample size (mm) } & \multirow[t]{2}{*}{$\begin{array}{c}\text { Confining pressure } \\
\sigma_{3}(\mathrm{MPa})\end{array}$} & \multirow[t]{2}{*}{$\begin{array}{l}\text { Water pressure } \\
\text { difference }(\mathrm{MPa})\end{array}$} & \multirow[t]{2}{*}{$\begin{array}{c}\text { Average peak stress } \sigma_{1} \\
-\sigma_{3}(\mathrm{MPa})\end{array}$} & \multicolumn{2}{|c|}{$\begin{array}{c}\text { Hydraulic } \\
\text { conductivity } \\
\left(\times 10^{-}\right. \\
10 \mathrm{~cm} / \mathrm{s})\end{array}$} \\
\hline & & Height & Diameter & & & & Initial & Peak \\
\hline Siltstone & $461.3-462.2$ & 98.4 & 49.6 & 5 & 1.5 & 48.7 & 5.18 & 24.3 \\
\hline Mudstone & $466.2-467.1$ & 99.7 & 49.6 & 5 & 1.5 & 29.5 & 1.17 & 5.31 \\
\hline Fine sandstone & $550.2-551.1$ & 99.5 & 49.5 & 5 & 1.5 & 74.32 & 8.15 & 167.7 \\
\hline
\end{tabular}

For the coupling fluid-solid modeling, the rock mass was regarded as a porous medium, and the fluid flow in the porous medium was described by Darcy's law and the Biot fluid-solid equation:

$$
\left\{\begin{array}{l}
G \nabla^{2} u_{j}-(\lambda+G) \frac{\partial \varepsilon_{v}}{\partial x_{j}}-\frac{\partial p}{\partial x_{j}}+f_{x_{j}}=0, \\
K \nabla^{2} p=\frac{1}{S} \frac{\partial p}{\partial t}-\frac{\partial \varepsilon_{v}}{\partial t},
\end{array}\right.
$$

where $\lambda$ and $G$ are the Lame constants; $p$ is the pore water pressure; $\varepsilon_{v}$ is the volume strain; $\chi_{i}, \mu_{j}$, and $f_{x_{j}}$ are the coordinate, displacement, and volume force in the $j$ direction, respectively. $\partial p / \partial x_{j}$ reflects the influence of the seepage field on the solid skeleton of the porous medium. The pore pressure affects the effective stress of the solid skeleton, which in turn affects its deformation. Hence, $\partial \varepsilon_{v} / \partial t$ also reflects the effects of the volume deformation of the solid skeleton on the seepage field. The Biot equation can well reflect the interaction between the pore pressure dissipation and the deformation of the solid skeleton of the porous medium. However, for the Biot equation, the hydraulic conductivity did not change with the stress. Therefore, to investigate the variation of hydraulic conductivity of surrounding rock during mining, we use the exponential equation to describe the changes of the hydraulic conductivity with the volume strain, which is also identified by the triaxial test that will be discussed later. On the other hand, the porosity is also relative to the volume strain. Exiting studies suggested that the porosity and the volume strain can be described by the following exponential formula $[8,29,30]$ :

$$
n=1-\left(1-n_{0}\right) e^{\varepsilon_{v}},
$$

where $n$ is the porosity and $n_{0}$ is the initial porosity. This formula will be adopted by the model of this study. For the FLAC $^{3 \mathrm{D}}$ model, the strain softening of rock was defined by the degradation of internal friction angle $(\varphi)$ and cohesion (c) with an increase in plastic strain $\left(\varepsilon^{p s}\right)$. The plastic strain adopts the following form in FLAC $^{3 \mathrm{D}}$ [31]:

$$
\varepsilon^{p s}=\sqrt{\frac{\left[\left(\Delta \varepsilon_{1}^{p s}-\Delta \varepsilon_{m}^{p s}\right)^{2}+\left(\Delta \varepsilon_{m}^{p s}\right)^{2}+\left(\Delta \varepsilon_{3}^{p s}-\Delta \varepsilon_{m}^{p s}\right)^{2}\right]}{2}}
$$

where $\Delta \varepsilon_{m}^{p s}=\left(\Delta \varepsilon_{1}^{p s}+\Delta \varepsilon_{3}^{p s}\right) / 3 ; \Delta \varepsilon_{1}^{p s}$ and $\Delta \varepsilon_{3}^{p s}$ are the plastic shear strain increment in the first and third main directions, respectively. According to the results of the triaxial hydraulic conductivity test, the changes of internal friction angle and the cohesion degradation with an increase in plastic strain are shown in Figure 2. We adopt the table function of the strain-softening model to calculate and present the internal friction angle $(\varphi)$ and cohesion $(c)$ reduction.

The FLAC ${ }^{3 \mathrm{D}}$ model was modified by replacing both constant hydraulic conductivity and porosity with both straindependent hydraulic conductivity and porosity using the fish code of FLAC ${ }^{3 \mathrm{D}}$. Both strain-dependent hydraulic conductivity and porosity were updated dynamically every 50 steps in the numerical simulation. The model used a rectangular parallelepiped with a length and width of $5 \mathrm{~cm}$ and a height of $10 \mathrm{~cm}$. The normal compressive stress of $5 \mathrm{MPa}$ was applied to the side to simulate the confining pressure. The rate of the upper and lower end faces of the rock sample was $4 \times 10^{-8} \mathrm{~m} / \mathrm{step}$. The top and bottom of the model were fixed water pressure boundaries. The top water pressure was $1.5 \mathrm{MPa}$, and the bottom water pressure was $0 \mathrm{MPa}$. The water pressure difference was $1.5 \mathrm{MPa}$. The model region was divided into 2000 grids. The parameters of the model are summarized in Table 2.

\section{Results and Discussion}

3.1. Triaxial Test. Figure 3 shows the measured stress-strain and hydraulic conductivity curves for different lithologies. First, the stress-strain behavior of all three rock samples experienced the following stages: compaction-elastic, deformation-yield, failure-strain, and softening-residual strength. However, for postpeak, the mudstone has stronger plasticity while the sandstone has stronger brittleness, which is caused by the differences in their structural properties. Second, the prepeak variation of rock was mainly compressive deformation, in which the hydraulic conductivity was relatively low. And both pore and fissures are close to the maximum. After the stress reached a peak, the hydraulic conductivity shows a sudden jump. At this time, the fissure inside the rock sample would have expanded, and the rock would have lost the ultimate bearing capacity. In the strain-softening stage, the new fissures would begin to close under the confining pressure, and the hydraulic conductivity of the three rock samples then decreased to varying degrees. Finally, the peak of hydraulic conductivity occurs in the strain-softening stage after rock failure. It indicated that the failure of the rock was not synchronized with the happening of the maximum hydraulic 


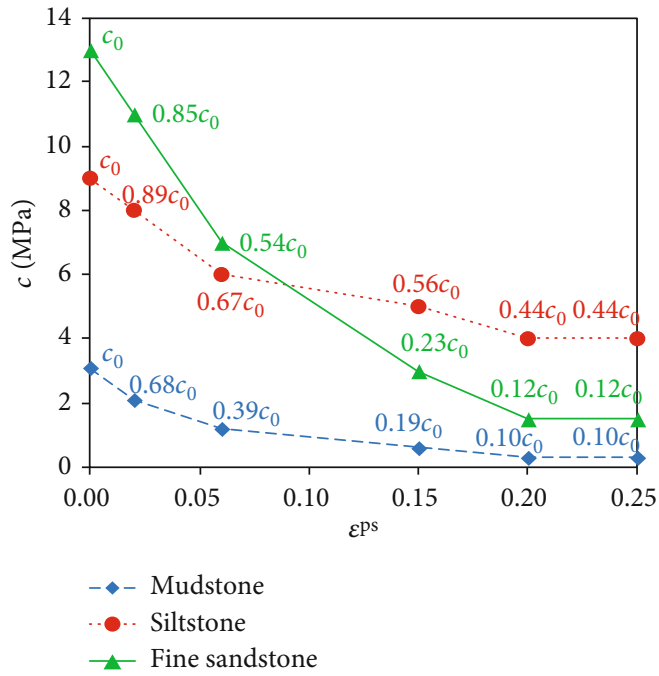

(a)

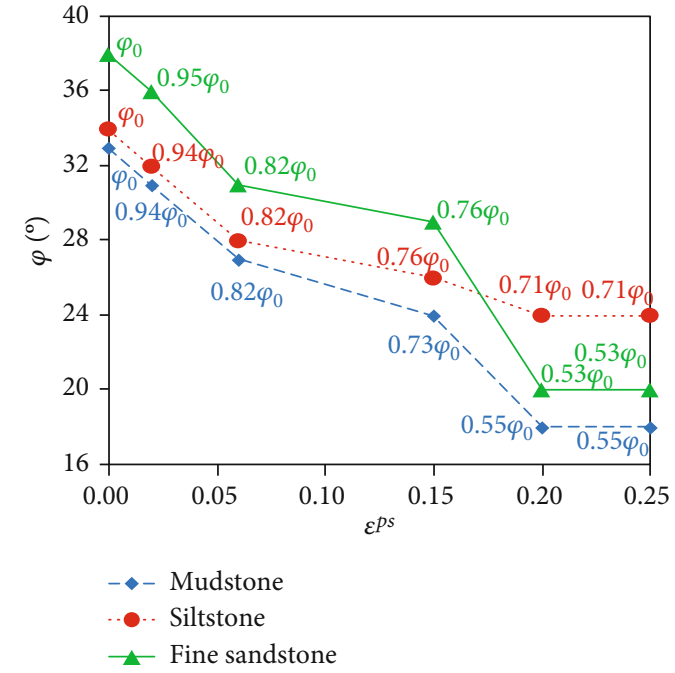

(b)

Figure 2: Changes of the shear strength parameters with the plastic strain $\left(\varepsilon^{p s}\right)$ for different rocks: (a) cohesion $(c)$ and (b) internal friction angle $(\varphi)$.

TABle 2: Parameters of the numerical model for the triaxial hydraulic conductivity test.

\begin{tabular}{|c|c|c|c|c|c|c|c|c|c|}
\hline Lithology & $\begin{array}{l}\text { Density } \\
\left(\mathrm{kg} / \mathrm{m}^{3}\right)\end{array}$ & $\begin{array}{c}\text { Hydraulic } \\
\text { conductivity }\left(\times 10^{-}\right. \\
10 \mathrm{~cm} / \mathrm{s})\end{array}$ & Porosity & $\begin{array}{c}\text { Elastic } \\
\text { modulus } \\
(\mathrm{GPa})\end{array}$ & $\begin{array}{l}\text { Poisson's } \\
\text { ratio }\end{array}$ & $\begin{array}{c}\text { Cohesion } \\
(\mathrm{MPa})\end{array}$ & $\begin{array}{c}\text { Internal } \\
\text { friction angle } \\
\left({ }^{\circ}\right)\end{array}$ & $\begin{array}{c}\text { Tensile } \\
\text { strength } \\
(\mathrm{MPa})\end{array}$ & $\begin{array}{c}\text { Dilatancy } \\
\text { angle }\left(^{\circ}\right)\end{array}$ \\
\hline $\begin{array}{l}\text { Fine } \\
\text { sandstone }\end{array}$ & 2600 & 8.15 & 0.2 & 5 & 0.2 & 13 & 38 & 6 & 28 \\
\hline Siltstone & 2550 & 5.18 & 0.15 & 2.3 & 0.23 & 9 & 34 & 4 & 24 \\
\hline Mudstone & 2500 & 1.17 & 0.12 & 1.45 & 0.3 & 3.1 & 33 & 3 & 22 \\
\hline
\end{tabular}

conductivity. The lowest values of hydraulic conductivity occur in the elastic stage. The test results showed that the hydraulic conductivities of mudstone, siltstone, and fine sandstone increases by $4.54,4.70$, and 20.58 times, respectively. It indicated that the growth rate of hydraulic conductivity of the brittle rocks is significantly higher than that of the plastic rocks.

Figure 4 displays the final fissure pattern of the typical rock samples. Under the action of water pressure and axial compression, the rock mainly splits or produces a highangle shear fracture. In addition, the rock was ruptured to form an inclined fissure plane that penetrates the entire rock sample when the rock fissure was not developed (Figure 4(a)). When the rock fissure developed, its failure mode was controlled by the structure plane, and the rock was mostly destroyed along the structure plane (Figure 4(b)).

3.2. Formula of Hydraulic Conductivity-Volume Strain. The triaxial test indicated that the larger the void space in the rock, the greater the hydraulic conductivity. Since the solid particles do not easily expand and contract. The expansion and contraction of the rock under triaxial conditions were mainly caused by the expansion and contraction of the void space. The changes in volume strain reflected the changes of the void space, which can be used to describe the evolution of rock hydraulic conductivity. Figure 5 shows the relationship between volume strain and hydraulic conductivity for the triaxial hydraulic conductivity test. Before yielding, the volume of rock samples decreased, and the volume strain was negative (the compressive strain). At this stage, the hydraulic conductivity generally decreased slowly. After yielding, several microcracks were generated, and the volume expanded. The volume strain increased sharply, resulting in a sudden peak in hydraulic conductivity. With further deformations, the fissure plane was sheared or worn, and the degree of fissure opening reduced. Under the action of confining pressure, the fissure had a certain degree of compaction closure, and the hydraulic conductivity decreased with the increase in volume strain. The variations of hydraulic conductivity of different rock samples after yielding obtained in this test are consistent with other researches [20-23].

To summarize, the volume strain can well reflect the changes in hydraulic conductivity of the rock before and after the stress peak appearing. On the basis of the experimental data, we can obtain the relationship between the volume strain and the hydraulic conductivity, which can be divided into two stages. According to Louis (1974), the hydraulic conductivity as a function of volume strain before the peak 


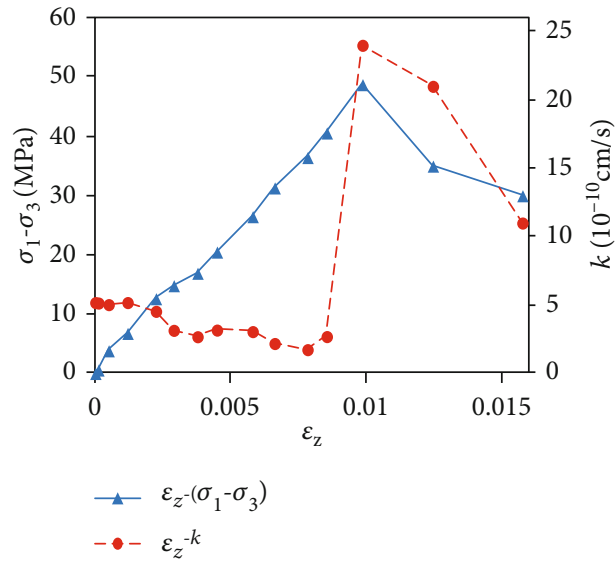

(a)

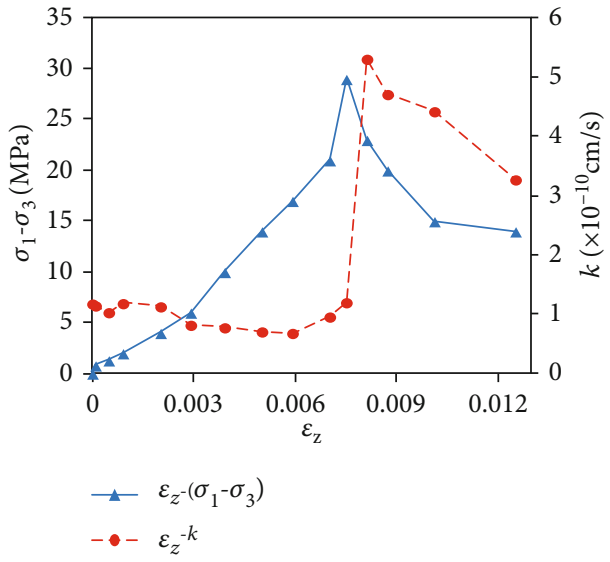

(b)

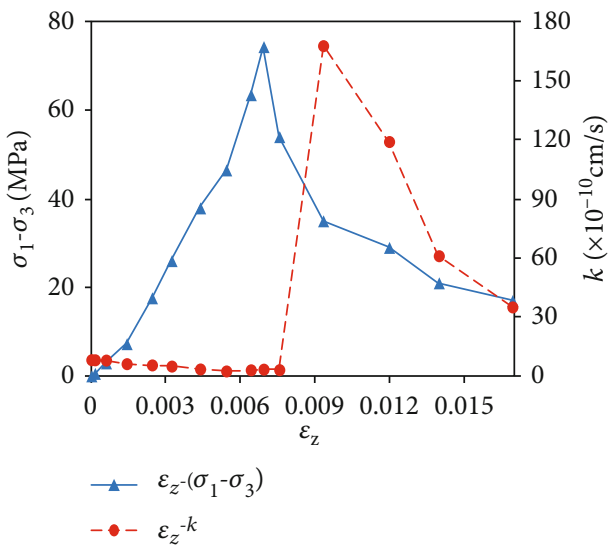

(c)

Figure 3: Deviatoric stress and hydraulic conductivity versus axial strain: (a) siltstone, (b) mudstone, and (c) fine sandstone.

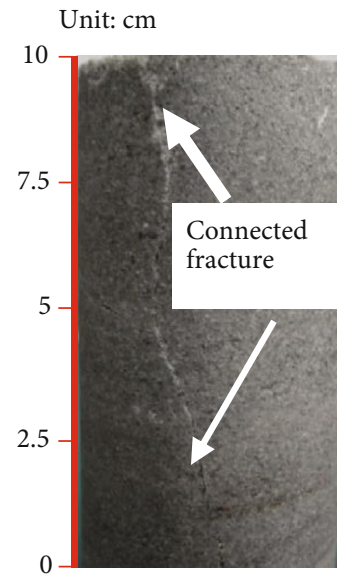

(a)

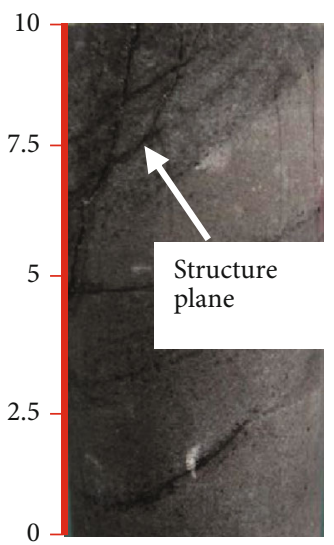

(b)

FIGURE 4: Observed cracks of rock samples in the triaxial test for (a) fine sandstone and (b) siltstone.

value appearing is given as

$$
K=K_{0} e^{\alpha_{1} \varepsilon_{v}}
$$

where $K_{0}$ is the initial hydraulic conductivity; $\alpha_{1}$ is a constant to describe the increasing rate of the hydraulic conductivity before its peak value appearing that is determined by the triaxial test. In the postpeak, the rock was destroyed with shear dilatation. Generally, hydraulic conductivity suddenly jumped. We can obtain the relationship between the 


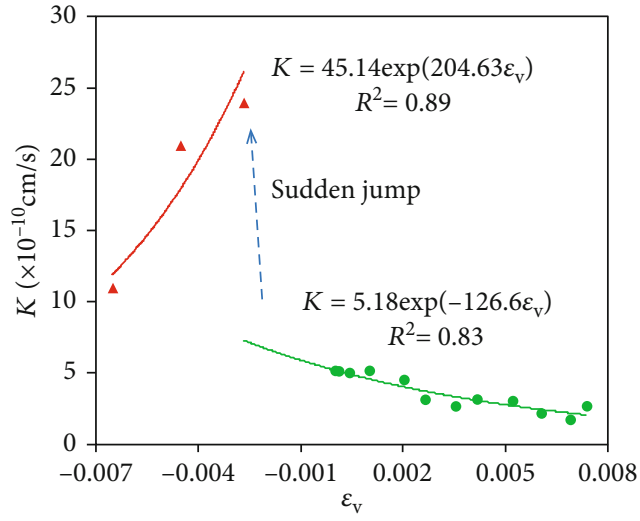

(a)

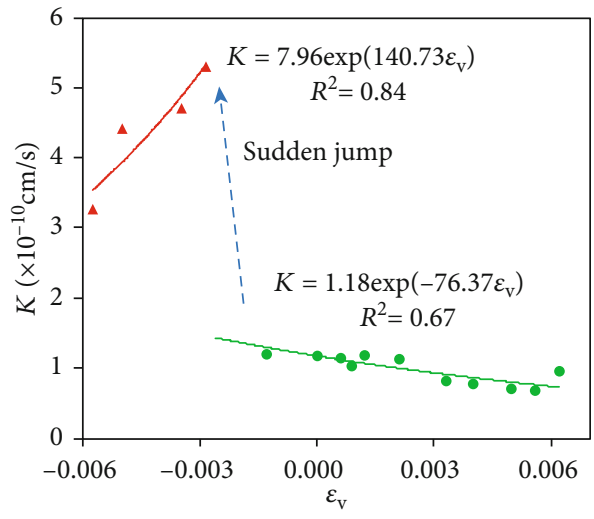

(b)

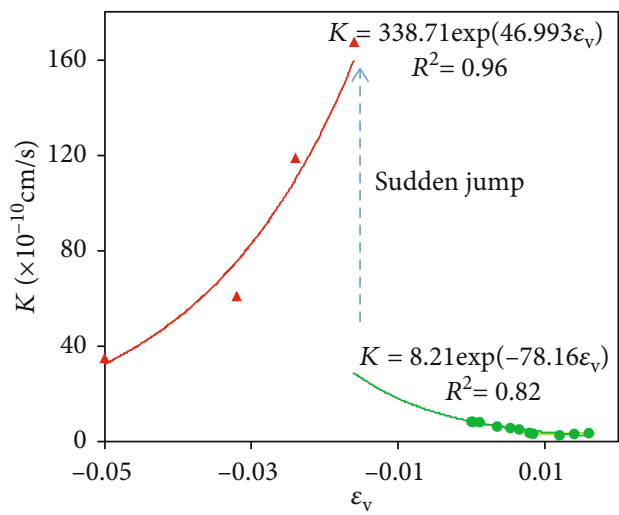

(c)

Figure 5: Relationship between volume strain and hydraulic conductivity: (a) siltstone, (b) mudstone, and (c) fine sandstone.

postpeak hydraulic conductivity and volume strain using the following formula:

$$
K=\xi K_{0} e^{\alpha_{2} \varepsilon_{v}},
$$

where $\alpha_{2}$ is a constant to describe the decreasing rate of the hydraulic conductivity after its peak value appearing that is also determined by the triaxial test; $\xi$ is the sudden jump coefficient of the hydraulic conductivity after yielding. The experimental data are fitted using equations (5) and (6) and are presented in Figure 5, showing that equations (5) and (6) agree well with the experimental data. It indicated that combining this formula into the FLAC ${ }^{3 \mathrm{D}}$ model is reliable to conduct the coupling fluid-solid modeling for describing the rock failure.

\subsection{Numerical Simulation of Triaxial Hydraulic Conductivity} Evolution of Rock Samples. Figure 6 displays the comparison of the stress-strain curves using numerical simulation and the triaxial test. It shows that the numerical simulations generally agree with the experimental data for three types of rocks. However, the errors in the prepeak stage were relatively large because the constitutive model used in the numerical model is assumed as a linear model that is not always true for the real case. Even so, the modified model can still reproduce the coupled fluid-solid processes and provide the appropriate prediction for water inrush in working faces, which will be further discussed in the section of the application.

Figure 7 shows the evolution of the hydraulic conductivity of sandstone sample for different loading stages using the numerical model. In the linear elastic phase (point $A$ ), elastic compression closed pore and fissure in the rock sample, and the hydraulic conductivity of the rock sample was lowered. When the stress reaches the yield limit (point $B$ ), the internal crack of the rock sample expanded. The hydraulic conductivity increased, and the shear band appeared. As the strain continued to increase, at point $C$, the rock sample first had a significant shear band at the top. Owing to the dilatancy expansion, the hydraulic conductivity of the rock sample in the shear zone increased sharply. As the fissures continue to grow, X-shaped through fissure was formed at point $D$. The hydraulic conductivity of the fissure zone was higher than that of the rock, and the maximum increase was 35 times compared with the initial hydraulic conductivity. After yielding, the fissure tended to close gradually, and the range of high hydraulic conductivity decreased step by step because of the confining pressure and is consistent with the previous experimental results. In addition, as seen in Figure 8, the apparent shear zone appeared after yielding, and the water flow converged on the X-shaped crack forming a significant dominant flow channel. 


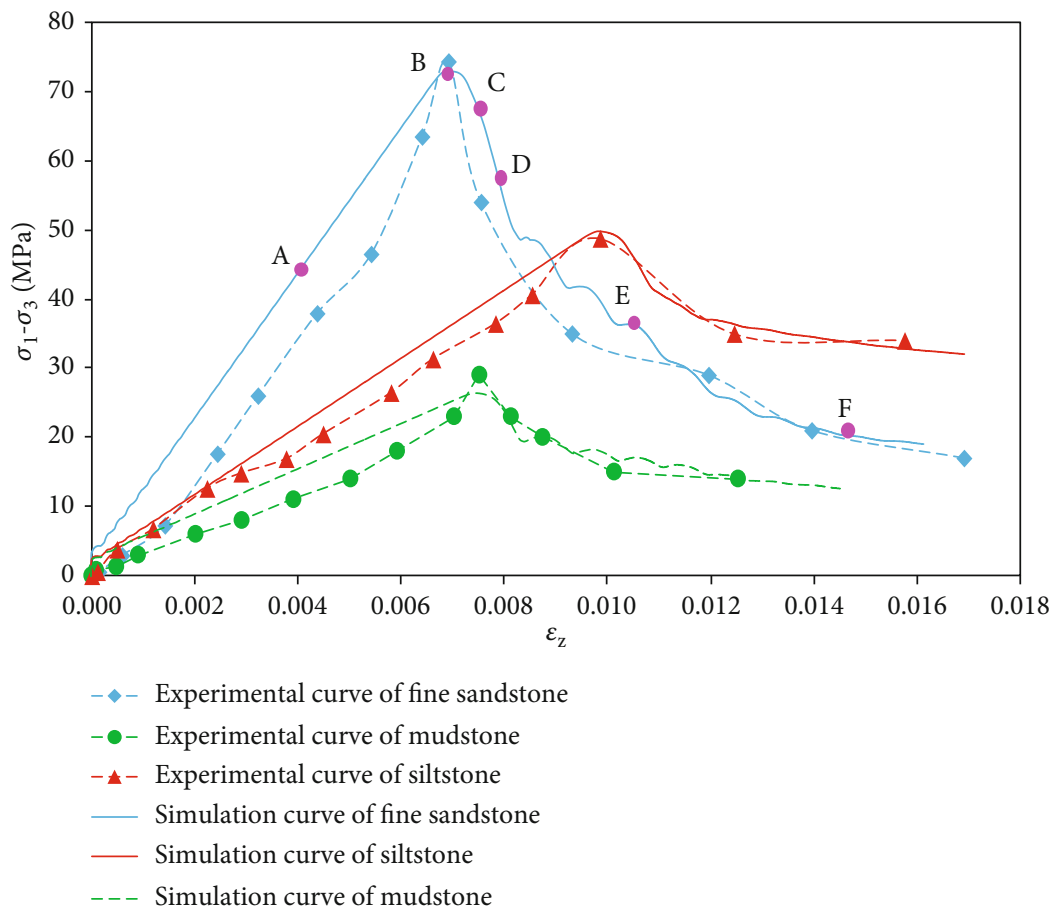

Figure 6: Comparison of the observed stress-strain curves with that of the numerical simulation.

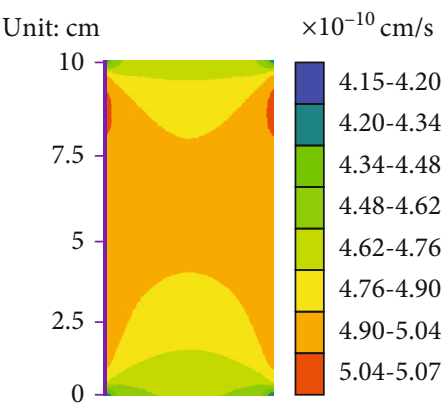

(a)

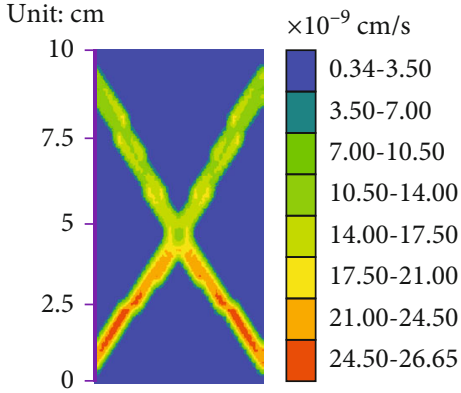

(d)

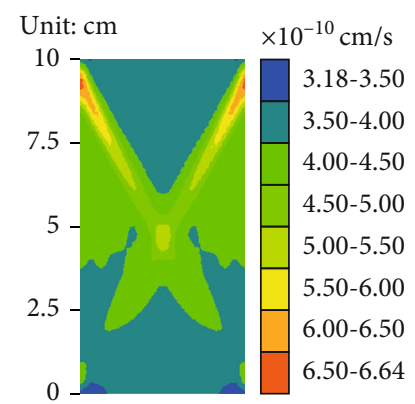

(b)

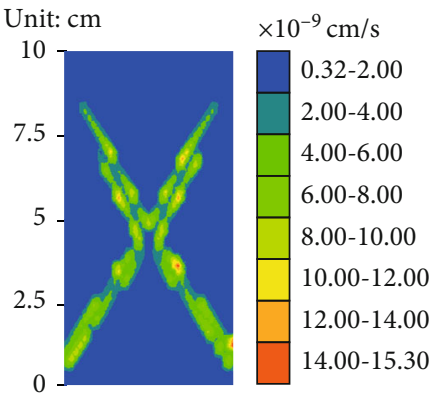

(e)

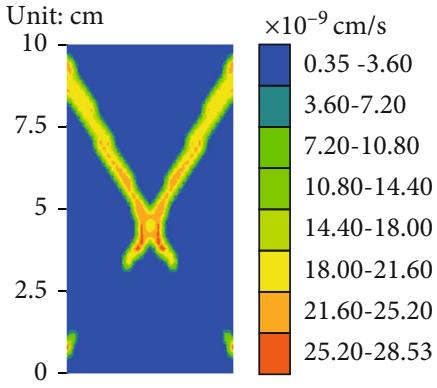

(c)

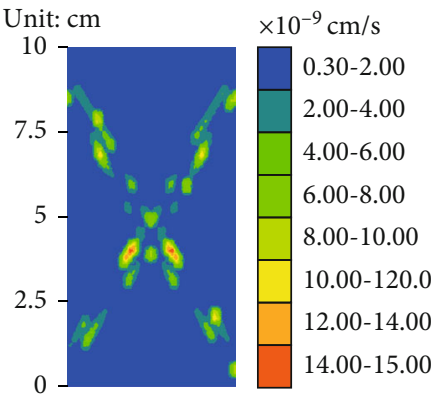

(f)

FIGURE 7: Contours of the hydraulic conductivity for the sandstone sample based on the numerical simulation for the different times: (a) point $A$, (b) point $B$, (c) point $C$, (d) point $D$, (e) point $E$, and (f) point $F$ in Figure 6.

\section{Application}

To further demonstrate the capacity of the modified model, it was applied for predicting water inrush in a worksite of Pansan coal mine of Huainan, China.
4.1. Geological Conditions of the Working Face. The 12318 working face is the first working face of the No. 8 coal seam in Pansan coal mine, which is in the east of the Xiyi mining area. The maximum length of the face is $2000 \mathrm{~m}$ along the strike, and the length of the tendency is $200 \mathrm{~m}$. The average 


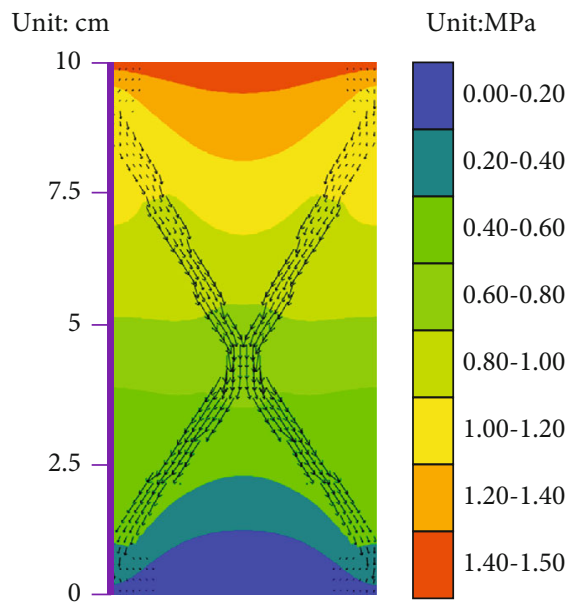

FIgURE 8: Contours of the pore water pressure and the directions of the seepage velocity after the fissure formation of the rock samples based on the numerical simulation.

dip angle and the thickness of the coal seam is $10^{\circ}$ and $3.5 \mathrm{~m}$, respectively. The average depth of the working face is $550 \mathrm{~m}$. Most of the seam roof is fine sandstone with an average thickness of $16 \mathrm{~m}$, which is characterized as medium thickness. The color of the roof is gray-white and belongs to the layered structure. Its composition is mainly quartz; the calcium cement is dense and hard with the fissures developed recently. The seam floor is mainly siltstone and fine sandstone.

According to the results of the water pumping test of the sandstone fracture aquifer in the mining area, the buried depth of the static water level is $200 \mathrm{~m}$. The unit water inflow and the hydraulic conductivity are $q=0.0133 \mathrm{~L} /(\mathrm{s} . \mathrm{m})$ and $K=1.08 \times 10^{-5} \mathrm{~cm} / \mathrm{s}$, respectively. The sandstone fracture was unevenly developed, and the local water richness was quite different. It is a direct source of water inrush which affects the safe mining of coal seams. Recently, the mining in this face has been affected by roof sandstone water.

\subsection{Numerical Model of Water Inflow in the Working Face.} The constitutive model used a strain-softening model with length, width, and height of $400 \mathrm{~m}, 400 \mathrm{~m}$, and $210 \mathrm{~m}$, respectively. The front, back, left, and right boundary conditions were fixed in the $x$ - and $y$-direction, while the floor had a full constraint boundary. The upper boundary of the model plus the load of $8.69 \mathrm{MPa}$ was equivalent to the self-weight of the overlying strata. For the prediction of water inflow, the normal compressive stress of $6.6 \mathrm{MPa}$ (crustal stress) was imposed to the side to simulate the confining pressure. Both top and floor of the working face are nonflow boundaries, and the other sides are pressure head boundaries. After the mining, the goaf becomes a drainage boundary. The 3-D model has 55480 units and 60372 nodes (Figure 9). The cohesion of the rock mass in Table 2 was reduced by $1 / 4$ based on previous studies [32] to account for the size effect. The layered thickness and the mechanical and hydraulic parameters of the numerical model are shown in Table 3. The relationship between the surrounding rock strength parameters $c$ and $\varphi$ and the plastic strain $\varepsilon^{p s}$ was obtained with reference to Figure 2. Excavation starts from the left side of the coal seam ( $x$-direction) at $125 \mathrm{~m}$ from the left side, and the working face width ( $y$-direction) was $200 \mathrm{~m}$. The hydraulic conductivity of the rock mass and the relationship between the porosity and the volume strain were simulated using the fish language as per equations (3), (5), and (6). The results of the triaxial hydraulic conductivity test were obtained under compression. According to the experimental research, the tensile fracture appeared in the rock, and the hydraulic conductivity increased significantly [23]. If a tensile failure occurred during the mining process, the sudden jump in hydraulic conductivity was considered as five times that of the shear failure.

The daily advancing speed of the working face was $10 \mathrm{~m} / \mathrm{d}$. To simulate daily footage, we adopted to excavate $10 \mathrm{~m}$ at each step in the numerical simulation. In the calculation process, the fluid module in $\mathrm{FLAC}^{3 \mathrm{D}}$ was first closed to calculate the mining response of the model in a single mechanical field. Next, we opened the fluid part and used the fluid-solid coupling to calculate the seepage field change under the current excavation step. The seepage calculation was completed for 1 day; then, we entered the next step of mining. The results show that the distance of the compaction area in goaf is generally about $100 \mathrm{~m}$. Therefore, a total of 10 steps $(100 \mathrm{~m})$ of mining were simulated.

4.3. Analysis of Simulation Results. Mining will affect the distribution of pore water pressure of surrounding rock. Taking the working face pushed to $100 \mathrm{~m}$ as an example, the distribution of surrounding rock water pressure was analyzed (Figure 10). The water pressure on the surrounding rock working face suddenly drops to zero after excavation, causing the fluid in the surrounding rock to flow to the goaf. The pore water pressure in the surrounding rock near the working face decreases significantly.

For reflecting on the variation characteristics of pore water pressure in surrounding rock during mining, the middle part of the $y$-direction of the model and an area $8 \mathrm{~m}$ below the coal seam floor was selected. The working face was advanced by $10 \mathrm{~m}, 30 \mathrm{~m}$, and $50 \mathrm{~m}$ to measure variations of the pore water pressure in the $x$-direction and is shown in Figure 11 . With the advancing working face, the goaf gradually increases. The pore water pressure in the vicinity of the goaf decreases obviously; the influence range increases with the goaf area, forming a cone of depression on the goaf. The trend line of pore water pressure on the floor was also advancing. When it is far away from the goaf, the pore water pressure distribution is less affected by mining, and the change is not obvious. However, when the working face passed the measurement point, the pore water pressure dropped rapidly. In addition, considering the change of hydraulic conductivity, the drop of water pressure at the same location was greater than that without considering the change of hydraulic conductivity. This was due to the obvious increase of hydraulic conductivity of roof and floor and the increase of water pressure drop near the working face caused by mining.

The ratio of the hydraulic conductivity of the surrounding rock to its original hydraulic conductivity $\left(K / K_{0}\right)$ in the coal mining process was calculated by using the FLAC ${ }^{3 \mathrm{D}}$ fish 


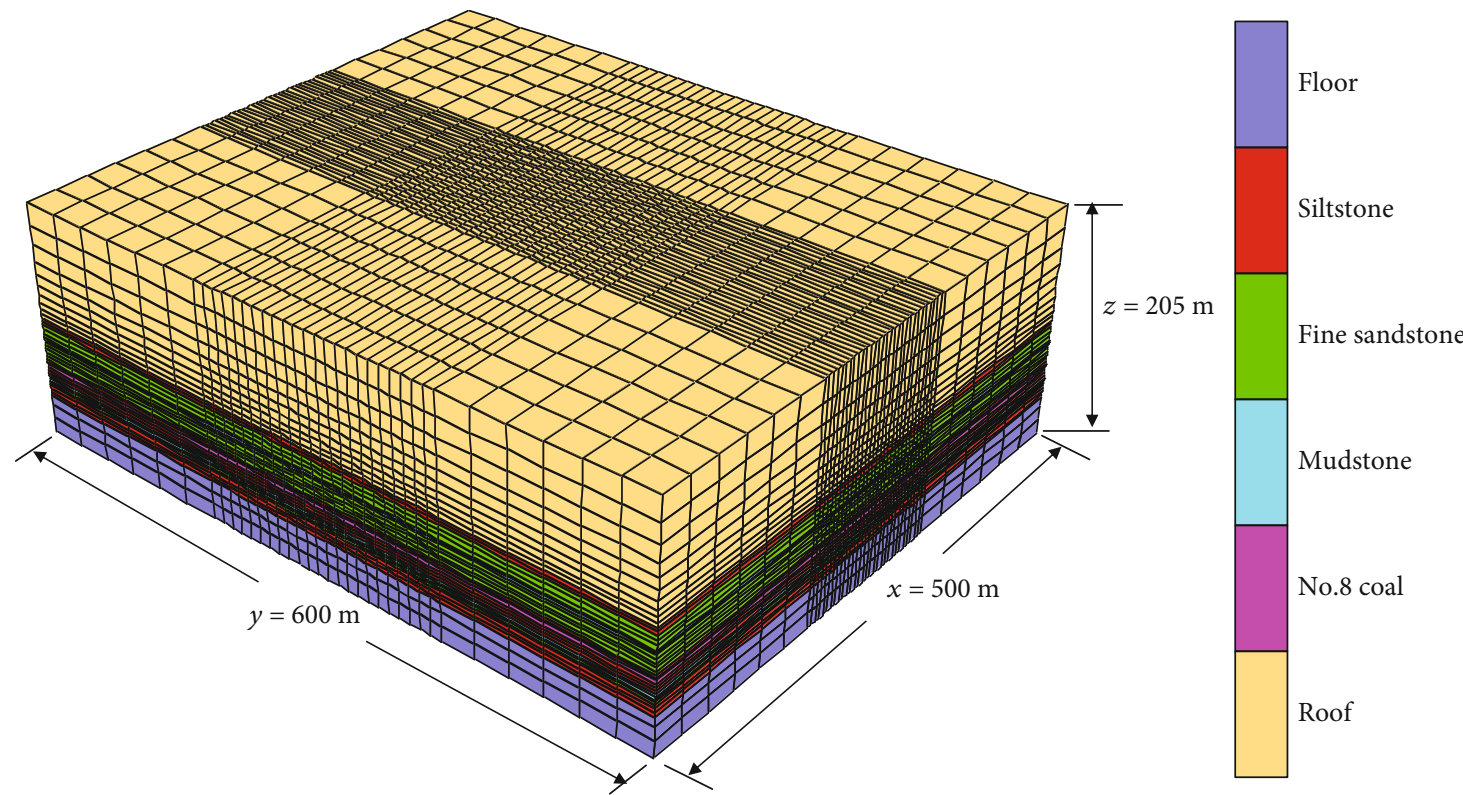

FIGURE 9: Grid mesh of the FLAC ${ }^{3 \mathrm{D}}$ model.

TABle 3: Parameters and lithology of the numerical model of water inrush in the working face.

\begin{tabular}{|c|c|c|c|c|c|c|c|c|c|c|}
\hline Lithology & $\begin{array}{c}\text { Thickness } \\
(\mathrm{m})\end{array}$ & $\begin{array}{l}\text { Density } \\
\left(\mathrm{kg} / \mathrm{m}^{3}\right)\end{array}$ & $\begin{array}{l}\text { Elastic } \\
\text { model } \\
(\mathrm{GPa})\end{array}$ & $\begin{array}{l}\text { Poisson's } \\
\text { ratio }\end{array}$ & $\begin{array}{c}\text { Cohesion } \\
(\mathrm{MPa})\end{array}$ & $\begin{array}{c}\text { Tensile } \\
\text { strength } \\
(\mathrm{MPa})\end{array}$ & $\begin{array}{c}\text { Internal } \\
\text { friction angle } \\
\left({ }^{\circ}\right)\end{array}$ & $\begin{array}{l}\text { Dilatancy } \\
\text { angle }\left(^{\circ}\right)\end{array}$ & $\begin{array}{c}\text { Hydraulic } \\
\text { conductivity } \\
\left(\times 10^{-6} \mathrm{~cm} / \mathrm{s}\right)\end{array}$ & Porosity \\
\hline Roof & 100 & 2600 & 5.00 & 0.25 & 3.0 & 2.6 & 32 & 24 & 10.8 & 0.2 \\
\hline Siltstone & 6 & 2550 & 2.30 & 0.27 & 2.6 & 2.5 & 32 & 23 & 3.0 & 0.15 \\
\hline $\begin{array}{l}\text { Fine } \\
\text { sandstone }\end{array}$ & 12 & 2600 & 5.00 & 0.25 & 3.0 & 2.8 & 32 & 24 & 10.8 & 0.2 \\
\hline Mudstone & 3.5 & 2500 & 1.45 & 0.35 & 1.3 & 1.0 & 30 & 22 & 1.0 & 0.1 \\
\hline $\begin{array}{l}\text { Fine } \\
\text { sandstone }\end{array}$ & 16 & 2600 & 5.00 & 0.25 & 3.0 & 2.8 & 32 & 24 & 10.8 & 0.2 \\
\hline Siltstone & 4 & 2550 & 2.30 & 0.27 & 2.6 & 2.5 & 32 & 23 & 3.0 & 0.15 \\
\hline No. 8 coal & 3.5 & 2000 & 1.40 & 0.3 & 1.2 & 1.0 & 28 & 22 & 1.0 & 0.1 \\
\hline Siltstone & 8 & 2550 & 2.30 & 0.27 & 2.6 & 2.5 & 32 & 23 & 3.0 & 0.15 \\
\hline Mudstone & 4 & 2500 & 1.45 & 0.35 & 1.3 & 1.0 & 30 & 22 & 1.0 & 0.1 \\
\hline $\begin{array}{l}\text { Fine } \\
\text { sandstone }\end{array}$ & 4 & 2600 & 5.00 & 0.25 & 3.0 & 2.8 & 32 & 24 & 10.8 & 0.2 \\
\hline Siltstone & 10 & 2550 & 2.30 & 0.27 & 2.6 & 2.5 & 32 & 23 & 3.0 & 0.15 \\
\hline Floor & 34 & 2600 & 5.00 & 0.25 & 4.0 & 3.2 & 32 & 24 & 10.8 & 0.2 \\
\hline
\end{tabular}

language as shown in Figure 12. The distribution diagram in Figure 12(a) shows the variation in hydraulic conductivity in the middle of the working face along the coal seam mining direction. The hydraulic conductivity of each rock mass in the roof and floor of the coal seam has changed greatly before mining because of the damage to the mining rock mass. At the direct roof and floor of the coal seam, due to the influence of tensile failure, the hydraulic conductivity of the siltstone increased to a maximum of approximately 25 times the original value. The variation of the roof hydraulic conductivity was saddle type, and that of the floor was eight shaped. This ratio decremented upwards and downwards from the goaf, which indirectly reflected the damage of the rock mass in the roof and floor. At different depths in the vertical direction (Figures 12(b)-12(e)), the roof and floor of the coal seam were affected by the mining in a certain range, and the hydraulic conductivity changed greatly. The maximum was usually at the coal wall of the working face. Due to abutment pressure, shear failure occurs here, along with volume strain expansion of rock mass, which results in increased hydraulic conductivity.

For reflecting on the dynamic variation characteristics in hydraulic conductivity of the surrounding rock during the mining, $8 \mathrm{~m}$ under the coal seam floor is taken for analysis 


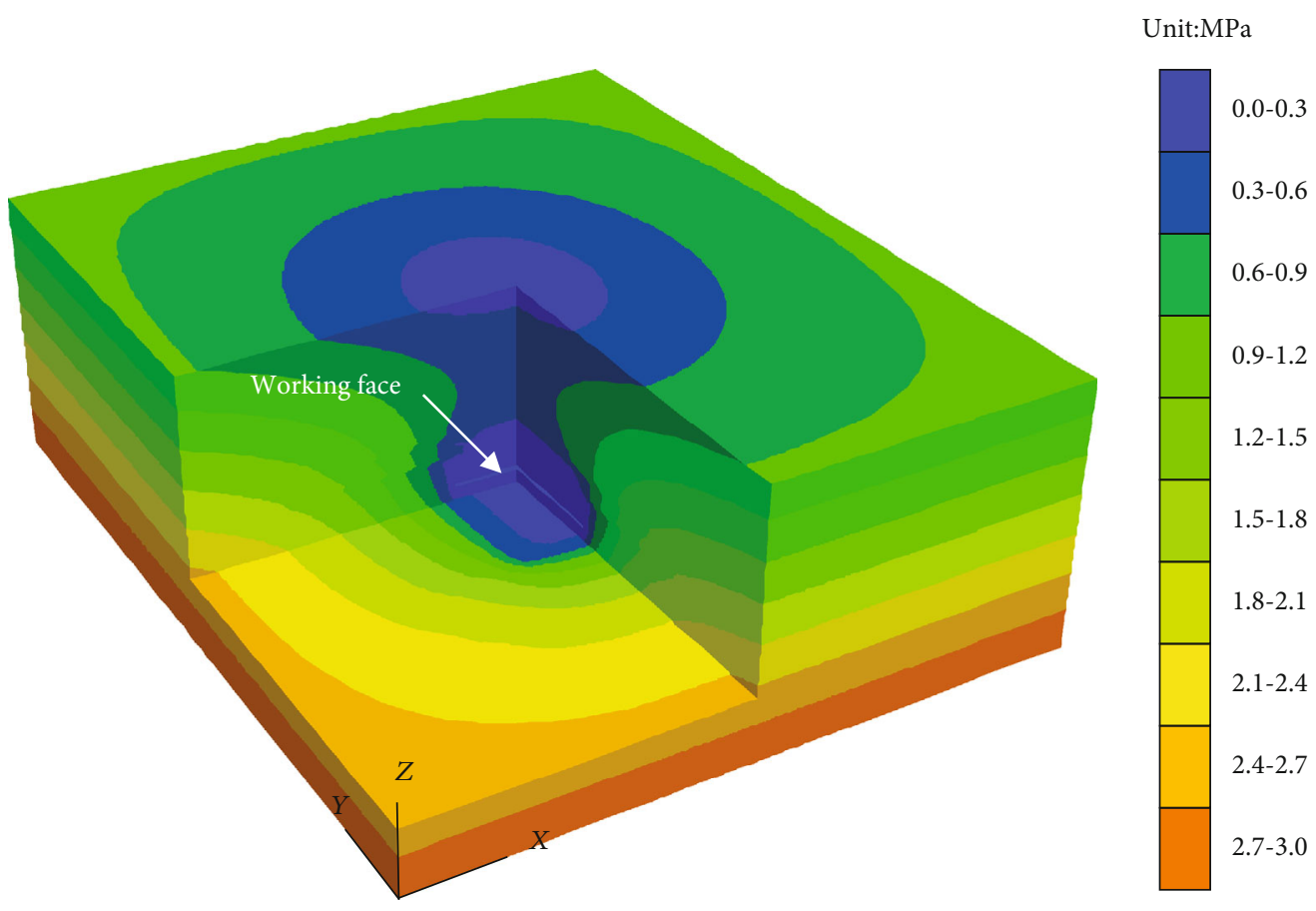

FIGURE 10: Distribution of the pore water pressure in the surrounding rock using the numerical modeling.

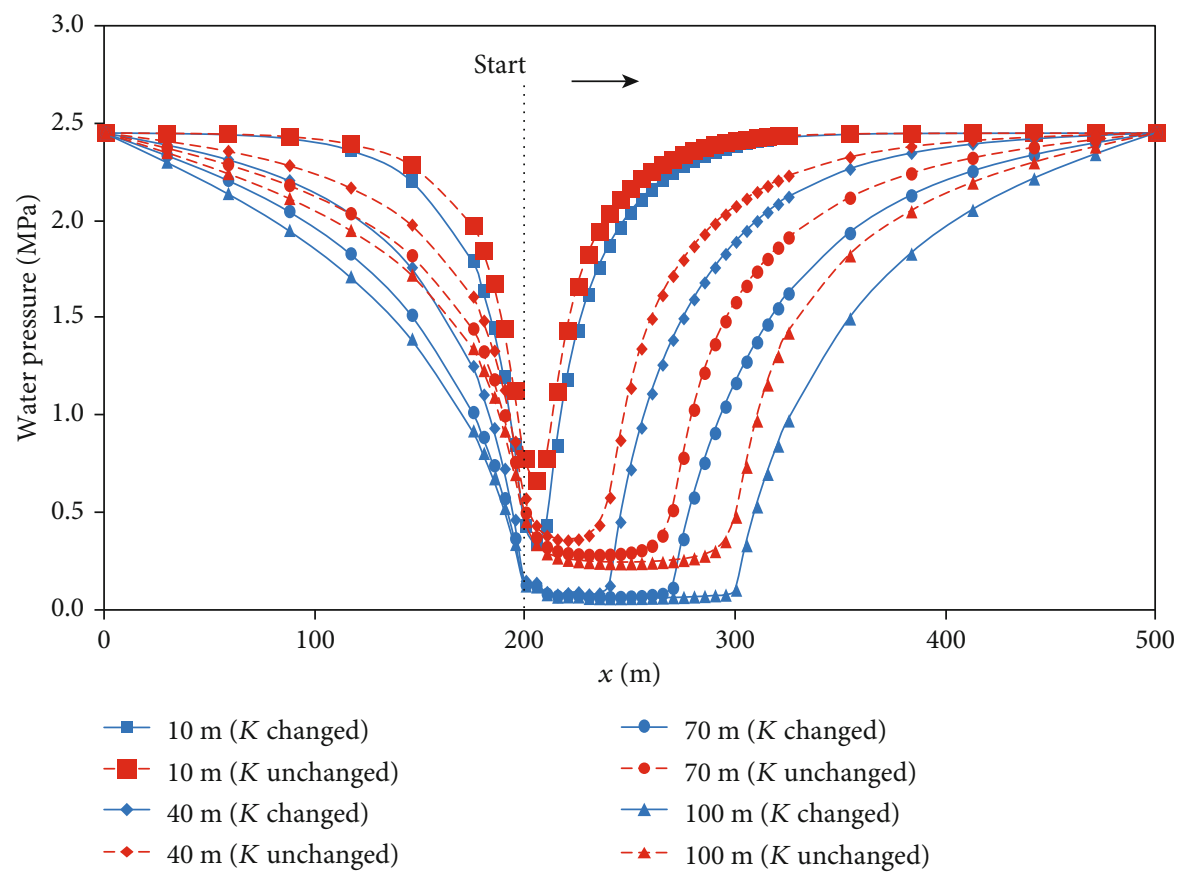

Figure 11: Distributions of the water pressure in $x$-direction using the modified (blue curves) and original (red curves) numerical models for the different lengths of the working face.

(middle section in $y$-direction of the model). The changing pattern of the hydraulic conductivity $\left(K / K_{0}\right)$ was made when the working face was propelled by $10 \mathrm{~m}, 40 \mathrm{~m}, 70 \mathrm{~m}$, and $100 \mathrm{~m}$ (Figure 13). It can be seen from Figure 13 that the hydraulic conductivity of the rock mass of the coal seam floor changed regularly with the advancing working face. The rock mass far away from the mining area was less affected by min- ing, and its hydraulic conductivity changed a little, which shows a declining state. When the working face was advanced by $10 \mathrm{~m}$, the floor rock mass at a depth of $8 \mathrm{~m}$ below the goaf was not damaged due to the small disturbance range, and the increase in hydraulic conductivity was not obvious. When the working face advanced distance was large, the hydraulic conductivity of the rock mass increased sharply 


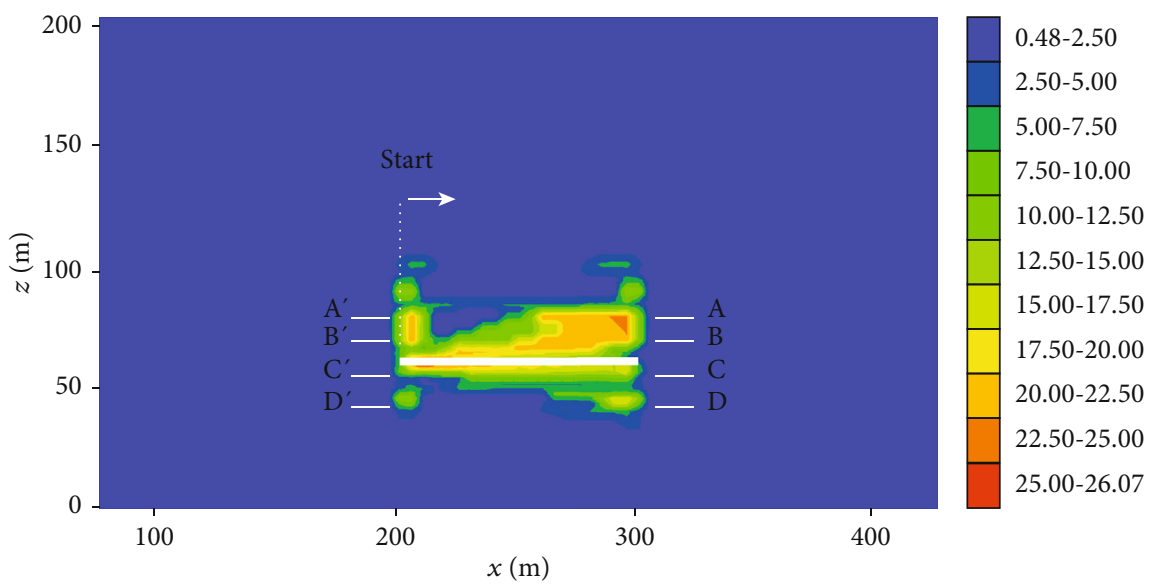

(a)

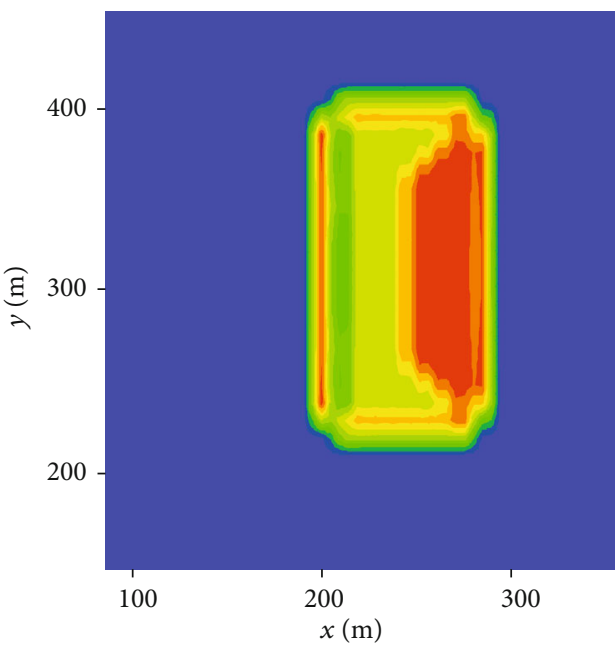

(b)

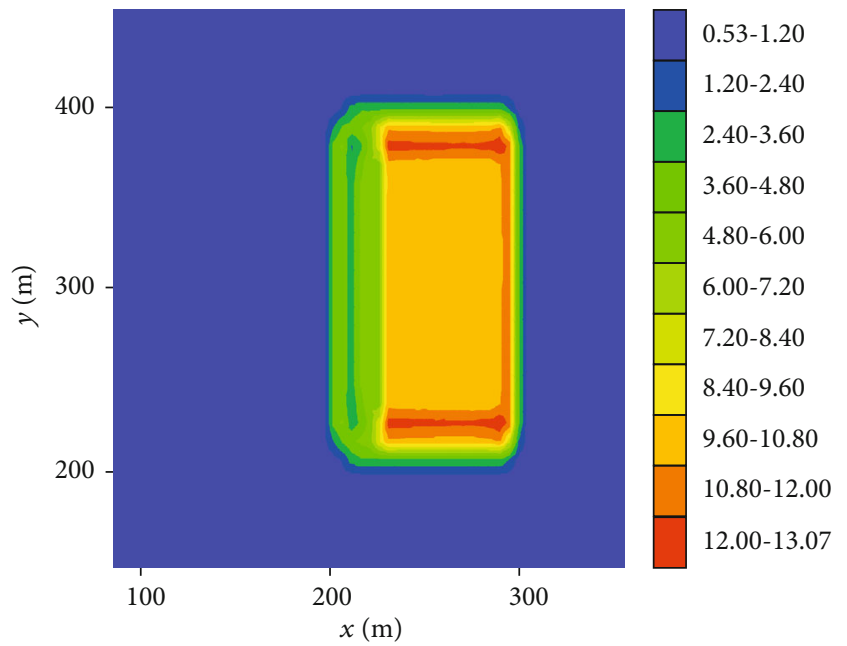

(d)

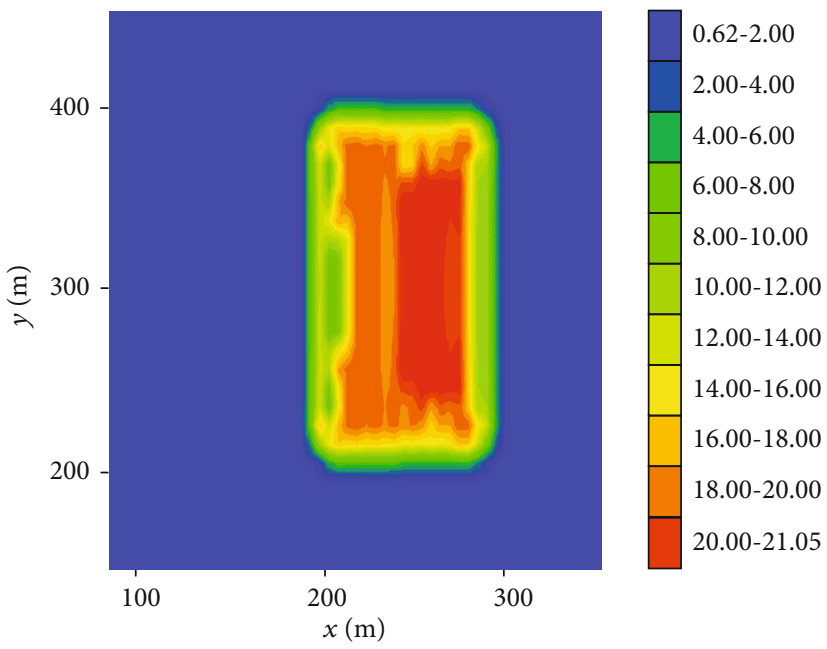

(c)

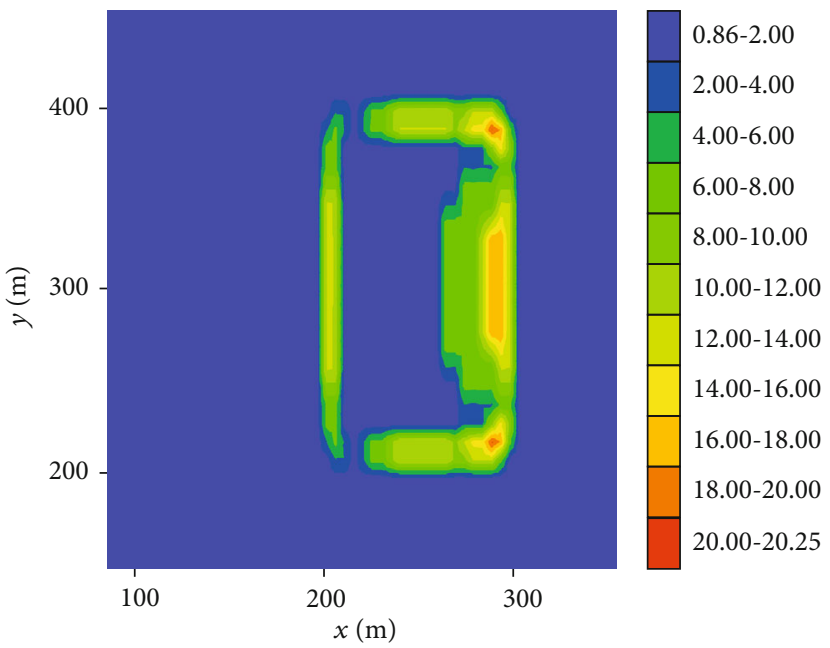

(e)

FIGURE 12: Contours of the hydraulic conductivity ratio $\left(K / K_{0}\right)$ using the modified numerical model with $100 \mathrm{~m}$ length working face for (a) strike section, (b) $A-A^{\prime}$ section (the fine sandstone of $17 \mathrm{~m}$ above the coal seam), (c) $B-B^{\prime}$ section (the fine sandstone of $7 \mathrm{~m}$ above the coal seam), (d) $C$ - $C^{\prime}$ section (the siltstone of $4 \mathrm{~m}$ below the coal seam), and (e) $D-D^{\prime}$ section (the fine sandstone of $14 \mathrm{~m}$ below the coal seam).

when it was deformed by mining. It should be noted that a small amount of undamaged rock mass appears at a region of $x=210 \sim 230 \mathrm{~m}$, and the permeability does not increase sharply. As the mining distance increased, the range of hydraulic conductivity increased. However, the increase gradually decreased with the advancing working face. As 


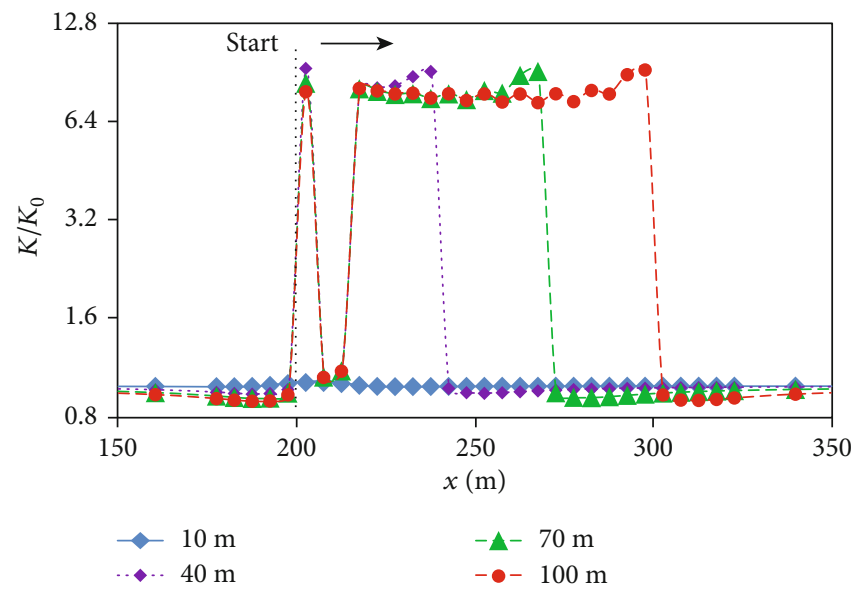

FIGURE 13: Distributions of the hydraulic conductivity of the coal-seam floor in $x$-direction using the modified numerical model for the different lengths of the working face.

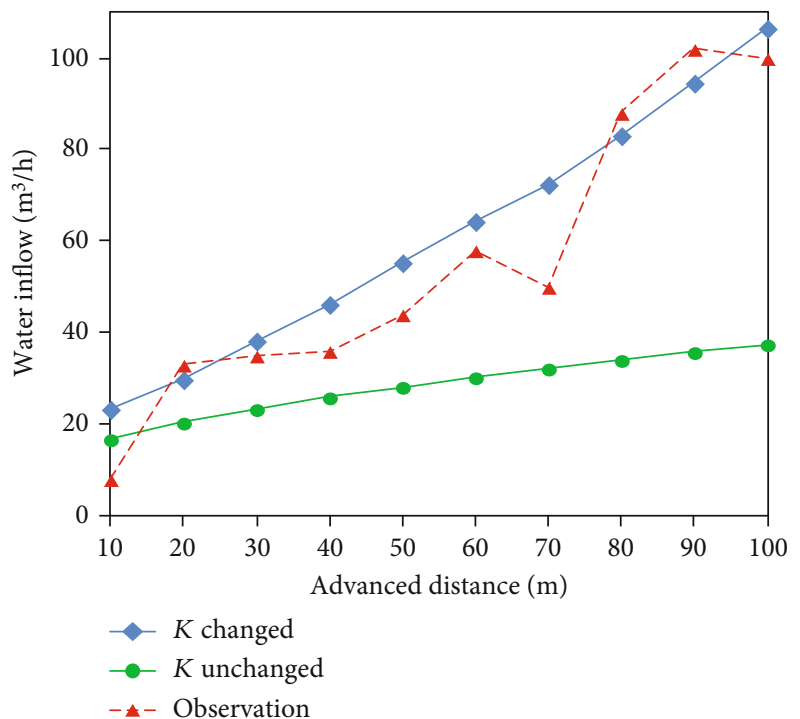

Figure 14: Comparisons of the water inflow from the working face of the observation, the original numerical model, and the modified numerical models for the different advanced distance (the length of the working face).

the rock mass fissure gradually closed under the confining pressure after yielding behind the working face, its hydraulic conductivity decreased even when the strain was increased. However, it was much larger than the initial hydraulic conductivity before mining and is consistent with the conclusion of the triaxial hydraulic conductivity test.

For the coupled fluid-solid model, the water inflow rate was calculated using the fish function (gp_flow) of FLAC ${ }^{3 \mathrm{D}}$, which is displayed in Figure 14. As the excavation area increased step by step, the amount of water inflow increased approximately linearly, from $23 \mathrm{~m}^{3} / \mathrm{h}$ to $106 \mathrm{~m}^{3} / \mathrm{h}$, with the advancing working face. When the influence of the mining disturbance on the hydraulic conductivity of the rock mass was not considered, the value of the water inflow became smaller. The difference gradually increased with the increase in the excavation area. The calculated values agreed with the measured water inflow values over ten consecutive days, when the hydraulic conductivity change was considered. The calculation accuracy was also higher even without considering changes in hydraulic conductivity.

The above results show that the hydraulic conductivity characteristics of rock mass change under mining conditions are large. However, the calculation results of the fixed value hydraulic conductivity should be used to forecast an actual water inflow to guide the safe production of coal mines correctly.

\section{Conclusions}

In this study, the hydraulic conductivity variations in rock samples during rock deformation and failure were measured using the triaxial servo rock mechanic test in a laboratory. The formula for the hydraulic conductivity-volume strain was proposed based on the experiment data. The finitedifference numerical model FLAC ${ }^{3 \mathrm{D}}$ was modified by replacing constant hydraulic conductivity with strain-dependent hydraulic conductivity. The coupled water flow and rock deformation and failure were simulated using the modified model. The modified model was then applied to a coal mining workface in Huainan, China. The main conclusions drawn from this study are as follows.

(1) The triaxial hydraulic conductivity test showed that the rock's hydraulic conductivity was not constant but varied with the evolution of the stress-strain process. In the elastic phase, elastic compression caused the pores and fissures in the rock samples to close, and the hydraulic conductivity decreased. When the stress reached the peak value, due to the dilatancy expansion, the hydraulic conductivity also increased sharply by 10-50 times its initial value. After the peak, the fissures tended to close gradually, and the hydraulic conductivity decreased gradually due to the confining pressure 
(2) Based on the test results, the exponential relationship formula between volume strain and hydraulic conductivity was proposed. Before yielding, they show a negative exponential relationship, while after yielding, they show a positive exponential relationship, and the formula has a high degree of fitting. The volume strain can better reflect the evolution of hydraulic conductivity during rock damage

(3) The coupling relationship between hydraulic conductivity and volume strain was incorporated into the relationship equation between the stress and seepage fields. This provided the governing equation for fluid-solid coupling numerical simulation of water inflow calculation in the coal working face. The FLAC ${ }^{3 \mathrm{D}}$ rock triaxial seepage coupling model was established, and then, the stress-strain curves of the calculated results were compared with those of the test results. The two were in good agreement, which proved that the fluid-solid coupling model established in this paper was successful

(4) The hydraulic conductivity and volume strain proposed in this paper was embedded in $\mathrm{FLAC}^{3 \mathrm{D}}$, and the fluid-solid coupling analysis was carried out for calculating water inflow from 12318 working face in Pansan coal mine of Huainan. The process of the hydraulic conductivity of the surrounding rock and the variation of the water inflow during the mining process were presented in an intuitive image dynamic. The simulation results of water inflow coincide with the actual observed values. In addition, the results are more accurate than that of the seepage model that does not consider mining disturbances

\section{Data Availability}

The data used in this study is available from Dr. Haifeng Lu (hflu@aust.edu.cn) upon request.

\section{Conflicts of Interest}

The authors declare that they have no conflicts of interest.

\section{Acknowledgments}

This work was supported by the National Natural Science Foundation of China (41977165 and 41977253), the major projects of natural science research in Higher Education Institutions of Anhui Province (KJ2019ZD11), the Central Public-interest Scientific Institution Basal Research Fund (GYZX190306), the Guangdong Provincial Key Laboratory of Soil and Groundwater Pollution Control (No. 2017B030301012), the State Environmental Protection Key Laboratory of Integrated Surface Water-Groundwater Pollution Control, and the Shenzhen Municipal Engineering Lab of Environmental IoT Technologies.

\section{References}

[1] L. Yuan, "Scientific problem and countermeasure for precision mining of coal and associated resources," Journal of China Coal Society, vol. 44, no. 1, pp. 1-9, 2019.

[2] X. M. Cheng, T. Z. Zhao, X. Q. Li, C. M. Li, and R. H. Sun, "Prediction of water inflow from the working face with strata bound water," Coalfield Geology and Exploration, vol. 4, pp. 34-37, 2007.

[3] J. J. Duan, H. J. Xu, and R. Prince, "Application of correlation analysis method in prediction of mine water inflow," Coal Science and Technology, vol. 41, no. 6, pp. 114-116, 2013.

[4] H. M. Wang and Y. Huang, "Prediction of mine water inflow by fuzzy hydrogeological analogy method in Changting mining area," Metal Mine, vol. 3, pp. 178-182, 2017.

[5] X. Chen, J. Yu, C.'a. Tang, H. Li, and S. Wang, "Experimental and numerical investigation of permeability evolution with damage of sandstone under triaxial compression," Rock Mechanics \& Rock Engineering, vol. 50, no. 6, pp. 1529-1549, 2017.

[6] C. Chen, W. Y. Li, and S. G. Xu, "Application of large diameter method in estimation water inflow of coal mine," Coal Technology, vol. 36, no. 11, pp. 199-201, 2017.

[7] L. K. Sahoo, S. Bandyopadhyay, and R. Banerjee, "Water and energy assessment for dewatering in opencast mines," Journal of Cleaner Production, vol. 84, pp. 736-745, 2014.

[8] K. Yang, B. H. Chen, and S. L. Shi, "Short-term prediction model of water inrush from coal mine floor based on HMM," Safety and Environmental Engineering, vol. 27, no. 5, pp. 190-196, 2020.

[9] L. Zhao, R. Ting, and N. B. Wang, "Groundwater impact of open cut coal mine and an assessment methodology: a case study in NSW," International Journal of Mining Science and Technology, vol. 27, no. 5, pp. 861-866, 2017.

[10] X. G. Cheng, W. Qiao, L. Lu, C. W. Jiang, and N. Lei, "Model of mining-induced fracture stress-seepage coupling in coal seam over-burden and prediction of mine inflow," Journal of China Coal Society, vol. 45, no. 8, pp. 2890-2900, 2020.

[11] L. Surinaidu, V. V. S. Gurunadha Rao, N. Srinivasa Rao, and S. Srinu, "Hydrogeological and groundwater modeling studies to estimate the groundwater inflows into the coal mines at different mine development stages using modflow, Andhra Pradesh, India," Water Resources \& Industry, vol. 7-8, pp. 4965, 2014.

[12] H. Lu, X. Liang, N. Shan, and Y.-K. Zhang, "Study on the stability of the coal seam floor above a confined aquifer using the structural system reliability method," Geofluids, vol. 2018, 15 pages, 2018.

[13] W. J. Sun, Q. Wu, H. L. Liu, and J. Jiao, "Prediction and assessment of the disturbances of the coal mining in kailuan to karst groundwater system," Physics and Chemistry of the Earth, Parts A/B/C, vol. 89-90, pp. 136-144, 2015.

[14] P. A. Charlez, Rock Mechanics Volume 2, Petroleum Applications, Technical Publisher, Paris, 1991.

[15] M. M. Tang, H. Y. Zhao, H. F. Ma, S. F. Lu, and Y. M. Chen, "Study on $\mathrm{CO}_{2}$ huff-n-puff of horizontal wells in continental tight oil reservoirs," Fuel, vol. 188, no. 15, pp. 140-154, 2017.

[16] M. Souley, F. Homand, S. Pepa, and D. Hoxha, "Damageinduced permeability changes in granite: a case example at the url in Canada," International Journal of Rock Mechanics \& Mining Sciences, vol. 38, no. 2, pp. 297-310, 2001. 
[17] J. A. Wang and H. D. Park, "Fluid permeability of sedimentary rocks in a complete stress-strain process," Engineering Geology, vol. 63, no. 3-4, pp. 291-300, 2002.

[18] S. J. Schatzel, C. Karacan, H. Dougherty, and G. V. R. Goodman, "An analysis of reservoir conditions and responses in longwall panel overburden during mining and its effect on gob gas well performance," Engineering Geology, vol. 127, pp. 65-74, 2012.

[19] D. P. Adhikary and H. Guo, "Modelling of longwall mininginduced strata permeability change," Rock Mechanics and Rock Engineering, vol. 48, no. 1, pp. 345-359, 2015.

[20] X. S. Liu, K. Wang, and M. Xu, "Permeability evolution of lowpermeability reservoir sandstone considering hydraulicmechanical-damage coupling effect during gradual fracturing process," Chinese Journal of Geotechnical Engineering, vol. 40, no. 9, pp. 1584-1592, 2018.

[21] X. Tan, H. Konietzky, and T. Frühwirt, "Laboratory observation and numerical simulation of permeability evolution during progressive failure of brittle rocks," International Journal of Rock Mechanics \& Mining Sciences, vol. 68, pp. 167-176, 2014.

[22] W. Wang, X. H. Li, and D. W. Hu, "Permeability evolution of brittle rock in progressive failure process under triaxial compression," Rock and Soil Mechanics, vol. 10, pp. 2761-2768, 2016.

[23] T. H. Yang, J. Liu, W. C. Zhu, D. Elsworth, L. G. Tham, and C. A. Tang, "A coupled flow-stress-damage model for groundwater outbursts from an underlying aquifer into mining excavations," International Journal of Rock Mechanics \& Mining Sciences, vol. 44, no. 1, pp. 87-97, 2007.

[24] E. Derek and B. Mao, "Flow-deformation response of dualporosity media," Journal of Geotechnical Engineering, vol. 118, no. 1, pp. 107-124, 1992.

[25] J. C. Stormont and J. J. K. Daemen, "Laboratory study of gas permeability changes in rock salt during deformation," International Journal of Rock Mechanics and Mining Science \& Geomechanics Abstracts, vol. 29, no. 4, pp. 325-342, 1992.

[26] W. F. Brace, J. B. Walsh, and W. T. Frangos, "Permeability of granite under high pressure," Journal of Geophysical Research, vol. 73, no. 6, pp. 2225-2236, 1968.

[27] C. A. Davy, F. Skoczylas, and J. D. Barnichon, "Permeability of macro-cracked argillite under confinement: gas and water testing," Physics and Chemistry of the Earth, vol. 32, no. 8-14, pp. 667-680, 2007.

[28] S. P. Li, Y. S. Li, and Z. Y. Wu, "Permeability-strain equations corresponding to the complete stress-strain path of Yinzhuang sandstone," International Journal of Rock Mechanics and Mining Sciences \& Geomechanics Abstracts, vol. 31, no. 4, pp. 383391, 1994.

[29] F. Cappa and J. Rutqvist, "Modeling of coupled deformation and permeability evolution during fault reactivation induced by deep underground injection of $\mathrm{CO}_{2}$," International Journal of Greenhouse Gas Control, vol. 5, no. 2, pp. 336-346, 2011.

[30] C. Y. Chin, R. Raghavan, and L. K. Thomas, "Fully coupled geomechanics and fluid flow analysis of wells with stress dependent permeability," SPE Journal, vol. 5, p. 48857, 2000.

[31] ITASCA, Fast Lagrangian Analysis of Continua, Version 5.0, Itasca Consulting Group Inc., Minnesota, 2012.

[32] S. P. Peng and J. A. Wang, Safe Coal Mining on Confined Water Bodies, Coal Industry Publishing, Beijing, 2001. 